\title{
Hubungan kadar hematokrit dengan tekanan darah pada pria dewasa muda obesitas sentral
}

\author{
${ }^{1}$ Nadiah D. Puspitarinie \\ ${ }^{2}$ Frans E. Wantania \\ ${ }^{2}$ Linda W. A. Rotty
${ }^{1}$ Kandidat Skripsi Fakultas Kedokteran Universitas Sam Ratulangi Manado
${ }^{2}$ Bagian Ilmu Penyakit Dalam Fakultas Kedokteran Universitas Sam Ratulangi Maando Email: nadiahrin@gmail.com

\begin{abstract}
Abdominal obesity is the accumulation of body fat in the abdomen that is most prevalent in males. The prevalence of abdominal obesity in Indonesia increased from 2007 (18.8\%) to $2013(26.6 \%)$ and North Sulawesi was the second rank of abdominal obesity among other provinces. Some studies suggested that there was a relationship between hematocrit, blood viscosity, and blood pressure, however, there is no study about these three parameters in young adult males with abdominal obesity so far. This study was aimed to determine the relationship between hematocrit and systolic blood pressure (SBP) as well as diastolic blood pressure (DBP) in young adult males with abdominal obesity. This was a cross-sectional analytical study in 42 male students aged 18-40 years of Faculty of Medicine, University of Sam Ratulangi Manado. The Spearman correlation test showed $\mathrm{r}=0.208$ and $\mathrm{p}=0.186$ for hematocrit level and SBP; and $\mathrm{r}=0.339$ and $\mathrm{p}=0.028$ for hematocrit level and DBP. Conclusion: There was a significant positive relationship between hematocrit and diastolic blood pressure but not with systolic blood pressure in male young adults with abdominal obesity.
\end{abstract}

Keywords: blood pressure, hematocrit, abdominal obesity

\begin{abstract}
Abstrak: Obesitas sentral adalah penumpukan lemak dalam tubuh di bagian perut, paling banyak terjadi pada pria. Prevalensi obesitas sentral di Indonesia mengalami peningkatan dari tahun 2007 (18,8\%) hingga tahun 2013 (26,6 \%) dimana Sulawesi Utara merupakan provinsi kedua tertinggi dengan obesitas sentral pada tahun 2013. Beberapa penelitian menyatakan bahwa terdapat hubungan antara kadar hematokrit, viskositas darah, dan tekanan darah namun penelitian secara khusus pada pria dewasa muda dengan obesitas sentral belum pernah dilakukan. Penelitian ini bertujuan untuk mengetahui hubungan kadar hematokrit dengan tekanan darah sistolik (TDS) dan diastolik (TDD) pada pria dewasa muda obesitas sentral. Jenis penelitian ialah analitik korelasi dengan desain potong lintang pada 42 mahasiswa pria usia 18-40 tahun di Fakultas Kedokteran Universitas Sam Ratulangi Manado. Hasil uji korelasi Spearman mendapatkan nilai $r=0,208$ dan nilai $p=0,186$ pada kadar hematokrit dengan TDS. Hasil uji korelasi Spearman mendapatkan nilai $r=0,339$ dan nilai $\mathrm{p}=0,028$ pada kadar hematokrit dengan TDD. Simpulan: Pada pria dewasa muda dengan obesitas sentral didapatkan hubungan bermakna antara kadar hematokrit dengan tekanan darah diastolik namun tidak dengan tekanan darah sistolik.
\end{abstract}

Kata kunci: tekanan darah, hematokrit, obesitas sentral

Obesitas sentral adalah penumpukan lemak dalam tubuh di bagian perut. Penumpukan lemak ini terjadi akibat kelebihan lemak pada jaringan lemak subkutan dan viseral. Faktor-faktor yang berhubungan dengan obesitas sentral ialah asupan makanan, 
aktivitas fisik dan umur. ${ }^{2}$ Obesitas tipe android biasanya terdapat pada pria dengan risiko masalah kesehatan yang lebih tinggi dibandingkan obesitas tipe gynecoid yang terdapat pada wanita. ${ }^{3,4}$

Menurut World Health Organization masalah yang sedang menjadi perhatian ialah pencegahan mengenai noncommunicable disease, yakni suatu kondisi medis dimana sebuah penyakit tidak menyebar melalui orang ke orang karena infeksi yang dapat diperburuk dengan semakin meningkatnya faktor risiko yang diantaranya adalah obesitas dan hipertensi.

Prevalensi penduduk laki-laki dewasa obesitas pada tahun 2013 sebanyak 19,7 persen, lebih tinggi dari tahun 2007 $(13,9 \%)$ dan tahun 2010 (7,8\%). Pada tahun 2013, prevalensi terendah di Nusa Tenggara Timur $(9,8 \%)$ dan tertinggi di provinsi Sulawesi Utara $(34,7 \%){ }^{6}$ Pada penelitian prevalensi obesitas pada mahasiswa Fakultas Kedokteran Universitas Sam Ratulangi tahun 2012 didapatkan bahwa $28 \%$ mahasiswa preobese, 3,9\% Obese I, dan 0,3\% Obese II. ${ }^{7}$ Prevalensi obesitas sentral di Indonesia mengalami peningkatan dari tahun 2007 (18,8\%) hingga tahun 2013 (26,6\%) dan Sulawesi Utara merupakan provinsi kedua tertinggi dengan obesitas sentral pada tahun 2013. ${ }^{6}$

Ketika beranjak dewasa dan masa dewasa awal, sebagian individu tidak menghiraukan bahwa gaya hidup akan memengaruhi kesehatan mereka nantinya, contohnya, pola makan tidak teratur, makan berlebihan, kebiasaan merokok, minum alkohol, tidak berolahraga, dan kurang tidur. Gaya hidup semacam ini terkait dengan kesehatan yang buruk, dan memengaruhi kepuasan hidup. ${ }^{8,9}$ Diketahui prevalensi hipertensi pada usia 18 tahun ke atas tahun 2007 di Indonesia sebesar 31,7\%. Komplikasi penyakit hipertensi antara lain penyakit jantung koroner (PJK), gagal ginjal, dan stroke sedangkan faktorfaktor risiko hipertensi ialah obesitas, kurang aktivitas fisik, dan stres. ${ }^{10}$

Penelitian Jae et al. ${ }^{11}$ menyimpulkan bahwa semakin tinggi kadar hematokrit maka semakin tinggi insidensi hipertensi bergantung pada faktor risiko. Diketahui dari penelitian sebelumnya bahwa terdapat hubungan antara kadar hematokrit dengan tekanan darah, namun belum pernah dilakukan penelitian secara khusus pada pria dewasa muda dengan obesitas sentral. Berdasarkan uraian diatas, penulis merasa tertarik untuk melakukan penelitian tentang hubungan kadar hematokrit dengan tekanan darah pada pria dewasa muda obesitas sentral.

\section{METODE PENELITIAN}

Jenis penelitian ini ialah analitik korelasi dengan desain potong lintang pada mahasiswa pria di Fakultas Kedokteran Universitas Sam Ratulangi Manado yang berusia $\geq 18$ sampai usia $<40$ tahun dan memiliki lingkar pinggang $\geq 90 \mathrm{~cm}$.

Sampel dipilih berdasarkan kriteria inklusi dan eksklusi, kemudian dilakukan pengukuran lingkar pinggang, pengukuran tekanan darah dengan menggunakan sphygmomanometer merkuri standar, dan pemeriksaan kadar hematokrit di laboratorium. Hasil penelitian dilakukan uji normalitas Kolmogorov Smirnov dilanjutkan dengan uji korelasi Spearman. Data disajikan dalam bentuk tabel dan grafik.

\section{HASIL PENELITIAN}

Berdasarkan penelitian yang dilakukan didapatkan 42 mahasiswa yang memenuhi kriteria penelitian dengan usia terendah 20 tahun dan usia tertinggi 39 tahun (rerata 23,67; simpangan baku 4,487). Nilai terendah untuk tekanan darah sistolik (TDS) $110 \mathrm{mmHg}$ dan nilai tertinggi 160 mmHg (rerata 131,67; simpangan baku 11,244). Tekanan darah diastolik (TDD) didapatkan nilai terendah $70 \mathrm{mmHg}$ dan nilai tertinggi $110 \mathrm{mmHg}$ (rerata 90,95; simpangan baku 10,075). Kadar hematokrit didapatkan nilai terendah $38,4 \%$ dan nilai tertinggi 54,6\% (nilai rerata 46,5; simpangan baku 2,982). Karakteristik lingkar pinggang didapatkan nilai terendah $90 \mathrm{~cm}$ dan nilai tertinggi $128 \mathrm{~cm}$ (rerata 101,976; simpangan baku 7,8157) (Tabel $1)$. 
Tabel 1. Karakteristik sampel secara umum

\begin{tabular}{lccccc}
\hline Variabel & N & Min & Maks & Mean & Std. Deviation \\
\hline Umur & 42 & 20 & 39 & 23,67 & 4,487 \\
TDS (mmHg) & 42 & 110 & 160 & 131,67 & 11,244 \\
TDD (mmHg) & 42 & 70 & 110 & 90,95 & 10,075 \\
Hematokrit $\%)$ & 42 & 38,4 & 54,6 & 46,5 & 2,982 \\
LP $(\mathrm{cm})$ & 42 & 90 & 128 & 101,976 & 7,8157 \\
\hline
\end{tabular}

Berdasarkan uji normal parameter dengan uji normalitas data Kolmogorov Smirnov, tekanan darah sistolik dan tekanan darah diastolik nilai $\mathrm{p}=0,000(<$ $0,05)$ yang berarti data tidak terdistribusi normal (Tabel 2).

Tabel 2. Hasil uji normalitas Kolmogorov Smirnov

\begin{tabular}{cc}
\hline Variabel & Nilai sig $(\mathbf{p})$ \\
\hline TDS & 0,000 \\
TDD & 0,000 \\
\hline
\end{tabular}

Berdasarkan uji Spearman yang dilakukan oleh karena distribusi data yang tidak normal, didapatkan hubungan positif $(\mathrm{r}=0,208)$ antara TDS dan hematokrit, walaupun secara statistik tidak bermakna $(\mathrm{p}=0,186)($ Tabel 3, Gambar 1).

Tabel 3. Hubungan kadar hematokrit dan TDS

\begin{tabular}{lccc}
\hline Variabel & N & $\begin{array}{c}\text { Spearman- } \\
\text { rho }\end{array}$ & $\boldsymbol{p}$ \\
\hline $\begin{array}{l}\text { Hematokrit } \\
\text { dengan }\end{array}$ & 42 & 0,208 & 0,186 \\
TDS & & & \\
\hline
\end{tabular}

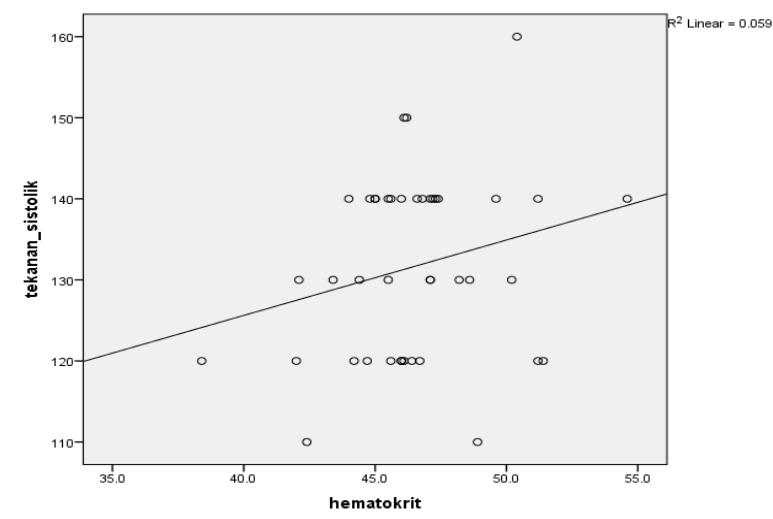

Gambar 1. Hubungan kadar hematokrit dengan TDS
Berdasarkan uji Spearman didapatkan hubungan positif $(\mathrm{r}=0,339)$ yang bermakna $(\mathrm{p}=0,028)$ antara TDD dan hematokrit, dengan kecenderungan semakin tinggi kadar hematokrit maka semakin tinggi TDS (Tabel 4, Gambar 2).

Tabel 4. Hubungan kadar hematokrit dan TDD

\begin{tabular}{lccc}
\hline Variabel & $\mathbf{N}$ & $\begin{array}{c}\text { Spearman- } \\
\text { rho }\end{array}$ & $\mathbf{p}$ \\
\hline $\begin{array}{l}\text { Hematokrit } \\
\text { dengan TDD }\end{array}$ & 42 & 0,339 & 0,028 \\
\hline
\end{tabular}

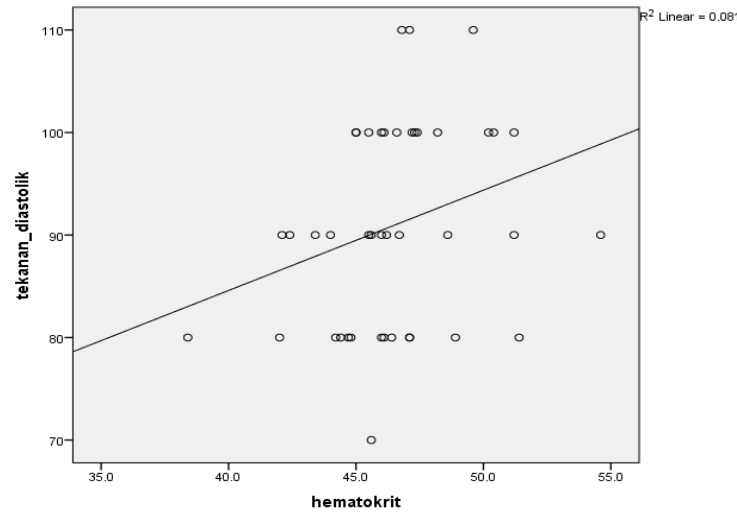

Gambar 2. Hubungan kadar hematokrit dan TDD

\section{BAHASAN}

Penelitian ini bertujuan untuk mengetahui hubungan antara kadar hematokrit dengan TDS dan TDD. Dalam penelitian ini terdapat 42 orang pria dewasa muda usia 18-40 tahun dengan obesitas sentral yang merupakan mahasiswa di Fakultas Kedokteran Universitas Sam Ratulangi. Penelitian dilakukan sejak awal bulan Oktober- November 2016.

Hasil penelitian ini menunjukkan bahwa terdapat hubungan positif antara kadar hematokrit dengan TDD maupun 
TDS yaitu semakin tinggi kadar hematokrit maka semakin tinggi tekanan darah. Hubungan bermakna didapatkan antara TDD dengan hematokrit ( $\mathrm{p}=0,028)$ namun tidak bermakna pada TDS dengan hematokrit $(\mathrm{p}=0,186)$.

Pada obesitas sentral terjadi peningkatan kebutuhan oksigen jaringan oleh karena kelebihan jaringan adiposa, sehingga terjadi kompensasi berupa pembentukan eritrosit untuk mengangkut lebih banyak oksigen ke jaringan yang berakibat meningkatnya kadar hematokrit dan hemoglobin yang dapat berpengaruh terhadap viskositas darah. ${ }^{11,12}$ Peningkatan viskositas darah dapat menurunkan laju aliran darah sekitar $16,67 \%$ sehingga memunculkan mekanisme kompensasi. $^{13}$ Jantung akan bekerja lebih keras untuk memompa darah ke seluruh tubuh. Makin keras usaha otot jantung dalam memompa darah, makin besar pula tekanan yang dibebankan pada dinding arteri sehingga meningkatkan tahanan perifer yang menyebabkan kenaikkan tekanan darah. ${ }^{14}$ Pada orang normal peningkatan curah jantung akan diikuti penurunan tahanan perifer untuk menjaga keseimbangan, namun pada orang obesitas dengan tekanan darah lebih tinggi dari optimal, tahanan perifernya dapat meningkat. ${ }^{15}$ Adanya ketergantungan antara tekanan darah arteri sistemik dengan curah jantung dan tahanan perifer menyebabkan TDS harus meningkat untuk mempertahankan curah jantung sehingga pada orang dengan obesitas peningkatan tekanan darah harus selalu diiringi peningkatan tahanan perifer untuk memastikan sirkulasi volume darah yang sama.

Penelitian yang serupa pernah dilakukan oleh Nishikido et al. ${ }^{16}$ terhadap 646 pekerja usia 18-41 tahun di Tokyo, Jepang menemukan bahwa terdapat hubungan positif antara kadar hematokrit dengan TDS dan TDD yang diuji dengan uji korelasi Pearson. Melalui uji Multiple Regression didapatkan bahwa hubungan antara hematokrit dengan TDD bermakna dan tidak bergantung dengan beberapa keadaan seperti usia, IMT, dan kebiasaan minum alkohol. Didapatkan pula hubungan antara hematokrit dengan TDS menjadi tidak bermakna setelah keadaan-keadaan diatas tidak diikutsertakan. Simpulan dari penelitian tersebut ialah adanya hubungan bermakna antara kadar hematokrit dengan TDD ( $<<0,001)$ tetapi tidak dengan TDS. ${ }^{16}$ Simone et al. ${ }^{17}$ dalam penelitiannya mengenai hubungan tekanan darah dengan viskositas darah menemukan bahwa whole blood viscosity (WBC) cenderung lebih tinggi pada pria, perokok, dan responden dengan obesitas sentral. Dalam temuannya juga dinyatakan bahwa TDD merupakan prediktor independen terhadap WBC dan kadar hematokrit namun hal yang sama tidak terbukti pada TDS. ${ }^{17}$ Disamping penemuan diatas, penelitian yang dilakukan oleh Cirillo et al. ${ }^{18}$ pada 2.809 responden yang terdiri dari pria dan wanita usia 25-74 tahun didapatkan hubungan bermakna antara kadar hematokrit dengan TDS dan TDD. ${ }^{18}$

Terdapat beberapa hal yang dapat menimbulkan perbedaan hasil penelitian seperti keragaman subjek penelitian dalam hal usia, jenis kelamin, latar belakang etnis, kebiasaan merokok, dan kondisi kesehatan tiap-tiap individu. Kebiasaan merokok dapat meningkatkan kadar hematokrit seseorang dan merupakan salah satu penyebab penyakit kardiovaskular. ${ }^{19,20}$ Usia juga dapat berpengaruh pada tekanan darah seseorang. Dengan menuanya seseorang maka akan terjadi mekanisme-mekanisme tertentu seperti disregulasi RAAS (Renin, Angiotensin, Aldosterone System), penyusutan pembuluh darah besar akibat proses degeneratif yang dapat meningkatkan TDS maupun TDD. ${ }^{21}$ Penelitian ini hanya dilakukan pada pria dewasa muda dan tidak ada yang termasuk lansia, sehingga proses degeneratif mungkin belum sepenuhnya terjadi dan juga dalam penelitian tidak terdapat perokok aktif.

\section{SIMPULAN}

Berdasarkan hasil penelitian dapat disimpulkan bahwa tidak terdapat hubungan bermakna antara kadar 
hematokrit dengan tekanan darah sistolik. Terdapat hubungan positif yang bermakna antara kadar hematokrit dengan tekanan darah diastolik.

\section{SARAN}

Perlu dilakukan penelitian lebih lanjut mengenai hubungan hiperviskositas, tekanan darah dan obesitas sentral dalam jumlah sampel yang lebih banyak dan cakupan yang lebih luas dengan memperhatikan kebiasaan hidup serta lamanya seseorang mengalami obesitas sentral.

\section{DAFTAR PUSTAKA}

1. Ilyas E. Keseimbangan diet; pengaturan asupan makanan; obesitas dan kelaparan; vitamin dan mineral. In: Widjajakusumah MD, editor. Guyton dan Hall Buku Ajar Fisiologi Kedokteran (12th ed). Singapura: Saunders Elsevier, 2014; p. 921-2.

2. Tchernof A, Després, JP. Pathophysiology of human visceral obesity. APS Journal. 2013;93:359-404.

3. Kyrou I, Randeva HS, Weickert MO. Clinical problems cause by obesity. 2014 April 14. [cited 31 Agustus 2016]. Available http://www.ncbi.nlm.nih.gov/books/ NBK278973/

4. Avrianda W. Hubungan asupan energi dengan obesitas pada siswa-siswi SMAN 9 Manado. [skripsi]. [Manado (Sulawesi Utara)]: Fakultas Kesehatan Masyarakat Universitas Sam Ratulangi; 2008.

5. World Health Organization. Noncommunicable disease. [cited 18 Agustus 2016]. Available from: http://who.int/gho/ncd/en/

6. Badan Penelitian dan Pengembangan Kesehatan RI. Riset Kesehatan Dasar 2013. [cited 18 Agustus 2016]. Available from: http://labmandat.litbang.depkes.go.id/i mages/download/laporan/RKD/2013/L aporan_riskesdas_2013_final.pdf.

7. Eka, Ticoalu SHR, Wongkar D. Prevalensi obesitas pada mahasiswa fakultas kedokteran Universitas Sam Ratulangi angkatan 2011. Jurnal Biomedik. 2012;4(3):591.
8. Hurlock BE. Psikologi perkembangan: suatu pendekatan sepanjang rentang kehidupan (5th ed). Jakarta: Erlangga, 1999; p. 246.

9. Kato L. Perkembangan fisik dan kognitif di masa dewasa awal. 2015 Oktober 3 [cited 19 Agustus 2016]. Available from:

http://www.ilmupsikologi.com/2015/10 / perkembangan-fisik-dan-kognitif-dimasa-dewasa-awal.html

10. Kementerian Kesehatan Republik Indonesia. Infodatin Pusat Data dan Informasi Kementerian Kesehatan RI Hipertensi. [cited 17 Agustus 2016]. Available from:

http://www.depkes.go.id/download.php ?file=download/pusdatin/infodatin/info datin-hipertensi.pdf.

11. Jae SY, Kurl S, Laukkanen JA, Heffernan KS, et al. Higher blood hematocrit predicts hypertension in men. Journal of Hypertension. 2014; 32:245-50.

12. Kembuan IY, Kandou G, Kaunang WPJ. Hubungan obesitas dengan penyakit hipertensi pada pasien poliklinik puskesmas Touluaan Kabupaten Minahasa Tenggara. eJournal Health. 2016;4:6-20.

13. Cinar Y, Demir G, Pac M, Cinar AB. Effect of hematocrit on blood pressure via hyperviscosity. AJH. 1999;12:73943.

14. Gilang YA. Korelasi derajat hipertensi dengan stadium penyakit ginjal kronik di RSUP Dr. Kariadi Semarang periode 2008-2012 [Skripsi]. Semarang: Fakultas Kedokteran Universitas Diponegoro; 2014.

15. Poirier P, Giles TD, Bray GA, Hong Y, Stern JS, Xavier F, et al. Obesity and cardiovascular disease: patophysiology, evaluation, and effect of weight loss. Circulation. 2006;113:898-918.

16. Nishikido N, Kobayashi T, Kashiwazaki H. Hematocrit correlates with blood pressure in young male office workers. Industrial Health. 1999;37:76-81.

17. Simone G, Devereux RB, Chinali M, Best LG, Lee ET, Welty TK. Association of blood pressure with blood viscosity in American Indians. Hypertension. 2005;45:625-30

18. Cirillo M, Laurenzi M, Trevisan M, Stamler J. Hematocrit, blood pressure, 
and hypertension. The Gubbio

Population Study. Hypertension. 1992;20:319-26.

19. Irawati L, Julizar, Irahmah M. Hubungan jumlah dan lamanya merokok dengan viskositas darah. Majalah Kedokteran Andalas. 2011;35:137-46.

20. Eso A, Hamra MY, Ahmadi AP. Hubungan hiperurisemia, obesitas, dan riwayat merokok dengan kejadian hipertensi. Medula. 2014;1:41-7

21. Parati G, Ochoa JE, Torlasco C, Salvi P, Lombardi C, Bilo G. Aging, high altitude, and blood pressure: a complex relationship. High Altitude Medicine and Biology. 2015;16:97-109. 